\title{
General Analysis of the Three-Phase Asynchronous Motor with Spiral Sheet Rotor. Operation, Parameters and Characteristic Values
}

\author{
Mujal-Rosas, Ramon and Orrit-Prat, Jordi
}

\begin{abstract}
The objectives of this article arise through the investigation of a motor with a high starting torque although with limited intensities, weak intensity variations depending on the load, controlled losses in no-load tests, and an acceptable performance in steady state and with a good response in transient periods. All these requirements would have to be obtained without the help of power electronics, in this way the motor would be more robust, longer lasting and without the need for auxiliary equipment. In this article, the operation principle, the characteristic parameters and the obtained results for the spiral sheet motor are analyzed for three speed regimes 1000 , 1500 and $3000 \mathrm{rpm}$. Also, at the end of the paper the spiral sheet motor is compared with the squirrel cage rotor, the solid rotor with rings, the wound rotor with additional resistances in the rotor circuit, and the hollow diamagnetic rotor.
\end{abstract}

Index Terms-Electric machines, Three-Phase Asynchronous motor, Spiral sheet rotor, Special machine.

\section{INTRODUCTION}

$\mathrm{N}$ owadays it has been widely used the industrial processes that require not only numerous start and stop cycles but also operation with load variations, i.e. textile industry, electrical household appliances or washing processes. Squirrel cage motors [1] [2] without auxiliary electronic devices have operating problems at high current values in different modes of operation, which implies inadmissible over-heating in their windings. Moreover, these motors usually work at very specific speed regimes and they lose most of their electrical, thermal or mechanical properties when the slip is modified (see fig. 1).

Solid rotor motors [3] [4] can work at different operating regimes, without having their current highly varied. Then, they can maintain their electrical and thermal properties more constant, but these properties are always lower than the ones of squirrel cage rotors.

The proposed asynchronous motor with spiral sheet rotor must be adapted to the different operating regimes without being assisted by power electronic devices. To achieve this goal, the current has little variation in start or stop cycles, even though these motors are working in any other regime.

Manuscript received December 1, 2009. Accepted for publication May 15, 2010. This work was supported by "Ministerio de Ciencia y Tecnología de España" under the DPI 2004-03180 Research Project.

Copyright (C) 2009 IEEE. Personal use of this material is permitted. However, permission to use this material for any other purposes must be obtained from the IEEE by sending a request to pubs-permissions@ieee.org

Ramon Mujal Rosas is with the Electrical Engineering Department of the Technical University of Catalonia. Colom St. 1, 08222 Terrassa, Spain (phone: 0034-93-739-8035; e-mail: mujal@ee.upc.edu).

Jordi Orrit Prat is with the Physics and Nuclear Engineering Department of the Thecnical University of Catalonia. Colom St. 11, 08222 Terrassa, Spain (e-mail: jordi.orrit@upc.edu).

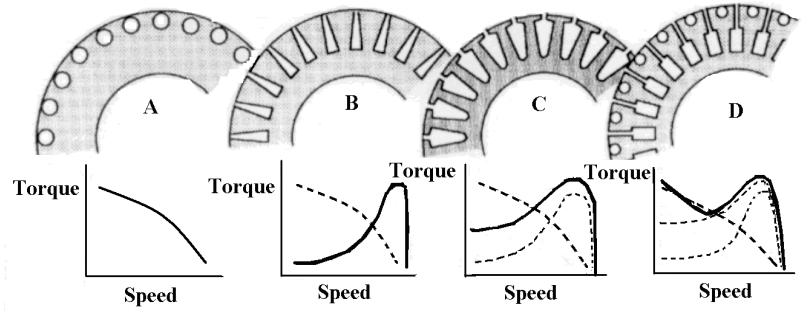

Fig. 1. Typical configurations of three-phase asynchronous motors.

Moreover, the torque, performance and other electrical magnitudes must have high values and remain constant at different speeds. What is more, the proposed motor must present good thermal and mechanic performance during all the time they are working.

To do this, eight variants of rotors with spiral sheets were constructed, all the same size, but with differences in the number of sheets, thickness, curvature radius, material used, position of the rings, etc. These rotors were tested with three equal stators but wound to 1000,1500 and 3000rpm. As well as this, the tests were validated using the Matlab-Simulink and FEMM program simulations. To complete the analysis, several more rotors were constructed: a solid rotor, hollow diamagnetic rotor [5] [6] [7], winding rotor [8]; and the results were compared to those of a commercial squirrel cage rotor.

For the purposes of this article and having considered the tests undergone (electrical, thermal, mechanical and magnetic) we wish to adopt the most balanced overall, spiral sheet Type A. Moreover, its sheet's curvature is the most appropriate to pile up all of its sheets and the material that has been considered presents lower losses and a normal saturation. This rotor has 270 no-isolated magnetic sheets which are $0.25 \mathrm{~mm}$ in thick and with losses of $4.6 \mathrm{~W} / \mathrm{kg}$ at $1.5 \mathrm{~T}$. The paper is focused in the motor with sheet rotor, and the general operation, the general equations and parameters, and the obtained results for the three operation regimes $(1000,1500$ and 3000rpm), are exposed and briefly compared with other induction motors more conventional that already have been studied in previous papers [9] [10] [11].

\section{PROTOTYPES DESCRIPTION}

As an example, the basic mechanical characteristics of some tested rotors [12] [13] [14] and [15], are presented in table I and fig 2. These rotors used have the same dimensions and they are assembled to stators of 1000, 1500 and $3000 \mathrm{rpm}$, the latter having the same constructive parameters. 
TABLE I

MAIN MECHANICAL CHARACTERISTICS OF ROTORS

\begin{tabular}{lcccccc}
\hline \hline \multicolumn{1}{c}{ Rotor types } & $\begin{array}{c}\text { Mass } \\
(\mathrm{kg})\end{array}$ & $\begin{array}{c}\text { Inertia } \\
\mathrm{Kgm}^{2}\end{array}$ & $\begin{array}{c}\text { Rotor } \\
\text { surface }\end{array}$ & Rings & $\begin{array}{c}\text { Num. } \\
\text { sheets }\end{array}$ & $\begin{array}{c}\text { Curve } \\
\text { sheets }\end{array}$ \\
\hline Squirrel cage & 3.440 & 2.717 & $\mathrm{M}$ & $\mathrm{S}$ & 150 & No \\
Solid with ring & 3.580 & 2.828 & $\mathrm{M}$ & $\mathrm{S}$ & solid & No \\
Hollow rotor & 3.025 & 2.384 & $\mathrm{M}$ & $\mathrm{S}$ & 125 & No \\
Winding rotor & 3.787 & 2.984 & $\mathrm{M}$ & $\mathrm{S}$ & 150 & No \\
Spiral sheet, A & 3.236 & 2.550 & $\mathrm{M}$ & $\mathrm{S}$ & 270 & $1^{\circ}$ \\
Spiral sheet, B & 3.359 & 2.647 & $\mathrm{~N} . \mathrm{M}$ & $\mathrm{S}$ & 270 & $1^{\circ}$ \\
Spiral sheet, C & 3.486 & 2.747 & $\mathrm{M}$ & $\mathrm{No}$ & 270 & $1^{\circ}$ \\
Spiral sheet, D & 3.080 & 2.427 & $\mathrm{M}$ & $\mathrm{S}+\mathrm{C}$ & 270 & $1^{\mathrm{o}}$ \\
Spiral sheet, E & 3.142 & 2.476 & $\mathrm{M}$ & $\mathrm{S}$ & 160 & $1^{\mathrm{o}}$ \\
Spiral sheet, F & 3.063 & 2.414 & $\mathrm{M}$ & $\mathrm{S}$ & 118 & $1^{\circ}$ \\
Spiral sheet, G & 3.185 & 2.510 & $\mathrm{M}$ & $\mathrm{S}$ & 270 & $2^{\mathrm{o}}$ \\
Spiral sheet, H & 3.094 & 2.438 & $\mathrm{M}$ & $\mathrm{S}$ & 270 & $3^{\mathrm{o}}$ \\
\hline \hline
\end{tabular}

Legend: Rotors dimensions: $79.5 \times 71 \mathrm{~mm}$; $\mathrm{I}=\mathrm{Inertia}\left(\mathrm{Kg} \cdot \mathrm{m}^{2} \times 10^{-3}\right)$ $\mathrm{M}=$ mechanized, N.M. $=$ no mechanized, $\mathrm{S}=$ side, $\mathrm{C}=$ central.

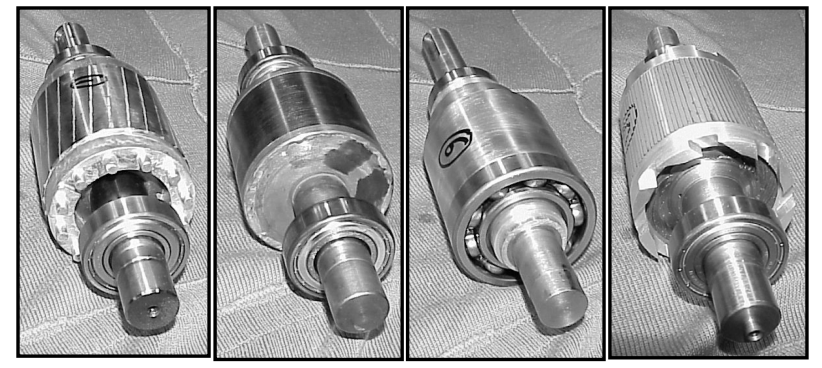

Fig 2. Rotors and stators used in the investigation. a) squirrel cage; b) solid rotor with rings; c) diamagnetic hollow rotor; d) spiral sheet rotor type A.

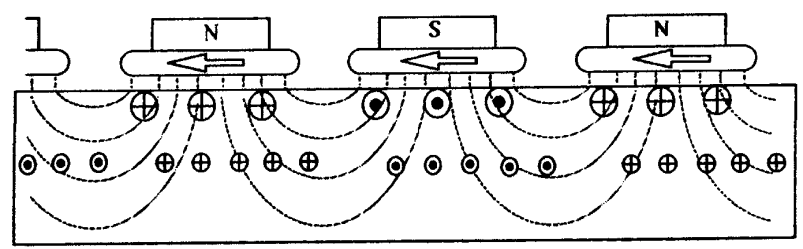

Fig. 3. The circulation of magnetic field lines.

\section{THREE PHASE ASYNCHRONOUS TORQUE MOTOR}

"Torque Motors" [16] were the motors on which we based the construction of our sheet prototype. These motors have a classically built stator, but the rotor is made up of a solid iron cylinder with small hysteresis cycle. With this type of rotor a greater useful flow passage section is obtained, due to the lack of slots, but with the disadvantage that their lines of magnetic field are deeper, creating weaker emfs which is in turn due to the smaller distance to the axis of the machine, as well as having greater reactance which lowers the power factor, although the losses in copper remain constant. Figure 3, shows how the deep currents are weaker, and therefore held up in the direction of displacement [17].
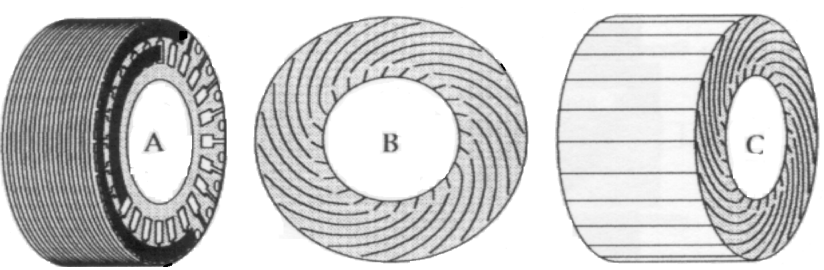

Fig. 4. Rotors: with double cage A. Spiral sheet rotors B and C types.

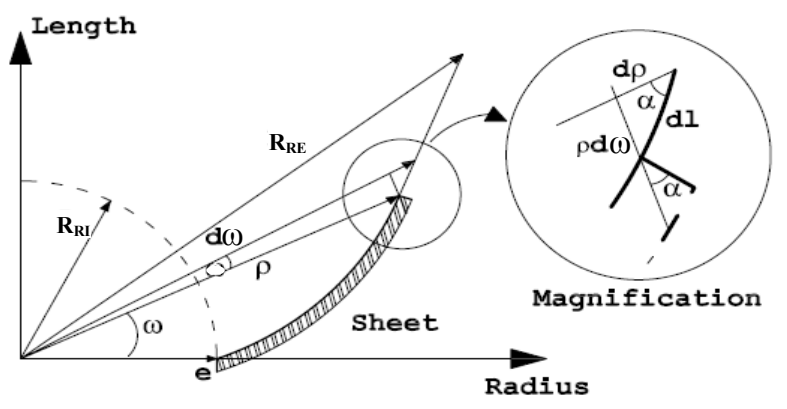

Fig. 5. Graph of geometric ratios.

\section{MOTOR WITH SPIRAL SHEET ROTOR}

To construct the sheet rotors [10] [11], [18] and [19], a completely different procedure is followed from that of the squirrel cage rotor [18]. The sheets are placed longitudinally with the edges applied directly over the rotor shaft, completely covering the rotor shaft's outer cylindrical surface. So as to remove the free spaces that would appear as the radial distance was increased, given that the sheet thickness is constant, the sheets are inclined, sweeping one over another, which results in a rotor made up of a set of spiral sheets as seen in figure 4.

These newly incorporated sheets do not have any slots, and therefore in order that they are perfectly connected and that there is not any air space between them, their silhouette has to show a well-defined profile as it is the evolving curve of a circumference, as it is shown in the trigonometric relations in figure 5 and equations (1) and (2). This profile is obtained by making adjustments using a machine tool or mold that bends each plate in a precise way.

Thus, if we consider a rotor with a inner radius $R_{R I}$, made up of $n$ sheets with a thickness $e$, where this thickness is very small in comparison with $R_{R I}$, and an outer radius $R_{R E}$ we will obtain the following relations which will allow us to find the sheet length $L_{\text {eng-sheet }}$ (equation 1) and the curvature radius $\rho$, by integrating equation (2) given in polar coordinates.

$$
\begin{gathered}
L_{\text {eng-sheet }}=\frac{\left(R_{R E}^{2}-R_{R I}^{2}\right)}{2 \cdot R_{R I}} \\
\frac{d \rho}{d w}=\frac{\rho}{\operatorname{tg} \alpha}=\frac{\rho}{\left(\frac{\operatorname{sen} \alpha}{\cos \alpha}\right)}=\frac{R_{R I} \cdot \rho}{\sqrt{\left(R_{R I}^{2}-\rho^{2}\right)}}=\rho^{\prime}
\end{gathered}
$$




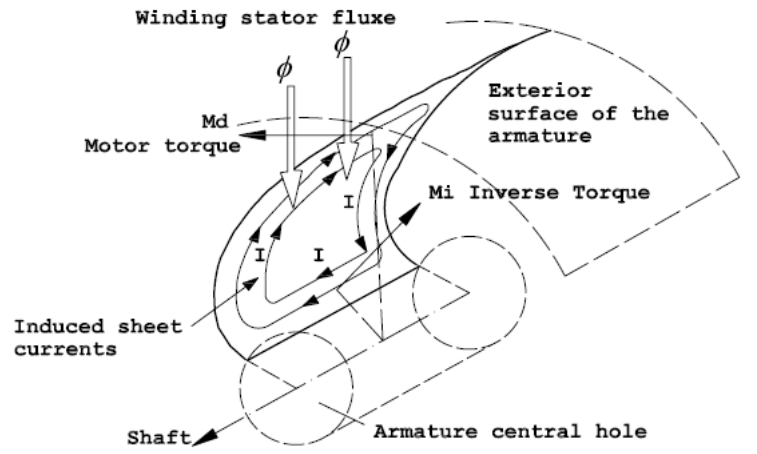

Fig. 6. Torque position, parasitic currents and magnetic field inside the sheets.

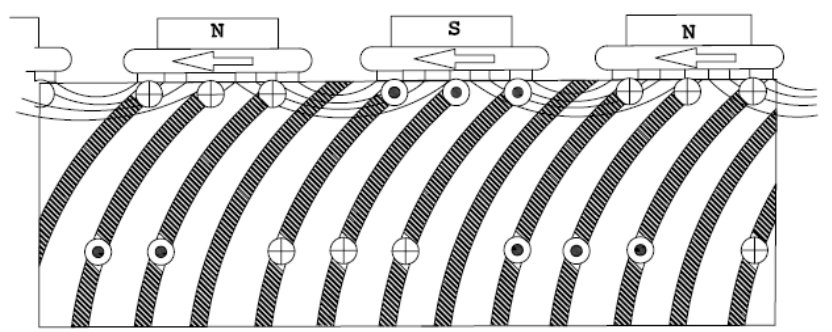

Fig. 7. Plane representation of sheet position. The pass and return areas of the active currents are indicated.

The configuration of the sheet drawn in figure 6 shows that it is possible that the magnetic fields created in the stator are more confined to the periphery of the rotor inducing more peripheral emfs and currents along the sheets, which are only active on the periphery. In this way, the revolving magnetic field generated in the stator windings, have an inclined way with respect to the sheets, which in turn produces parasitic currents in the sheets and when circulating with the flow presence already mentioned, generate antagonistic torque. The outside torque is greater than the inside torque, because it takes place at a greater radial distance, which results in a net moment of rotation of an equal value to the difference between the torques generated. So, with this sheet position, the peripheral currents have a greater area in which to circulate compared to currents in a squirrel cage rotor [19] [20].

Figure 7, shows a developed representation of the sheet's position in spiral shape, outlining the differences in two areas; the first where the active currents pass, feeding the second where the possible return currents are received. This return is normally established by the rings as a short circuit, and as a consequence the only important rotary resistance, and which corresponds to the outer areas of the magnetic sheets that make up the rotor, given that the rings display an insignificant resistance.

\section{MAGNETIC FIELD OF THE STATOR AND THE ROTOR}

The magnetic field created in the rotor, which depends on the value and depth in which the rotor currents circulate, will affect, if it is more superficial, the total magnetic field with greater current. The magnetic field created by the stator will follow a more conventional form crossing the space occupied by air and following a perpendicular trajectory when it crosses a sheet [21].

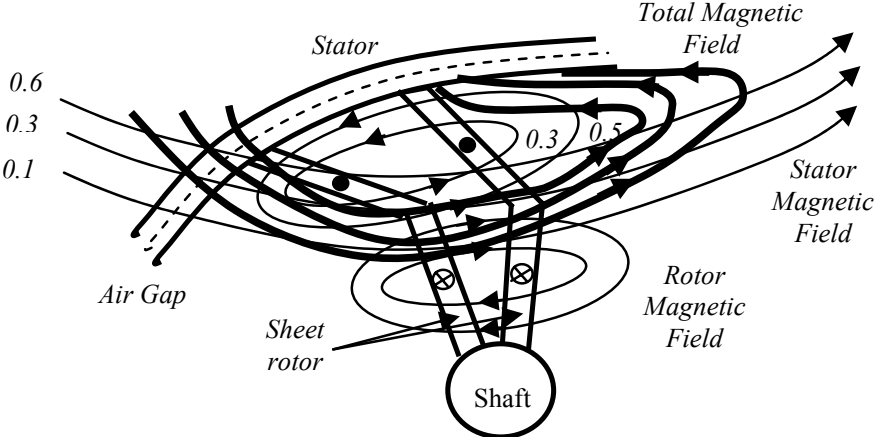

Fig. 8. Interaction between the magnetic fields of the stator and rotor in a sheet of the rotor.

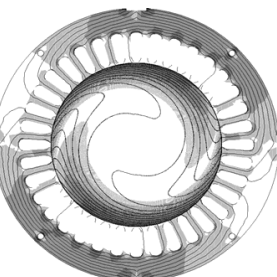

a)

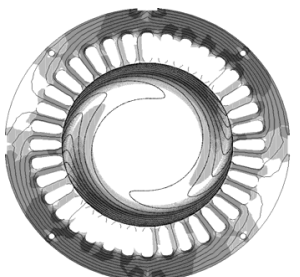

b)

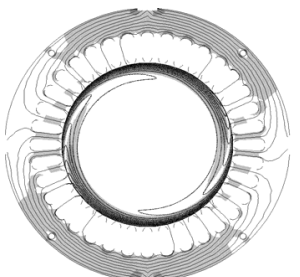

c)
Fig. 9. Total magnetic field for motors with spiral sheet rotor at $3000 \mathrm{rpm}$ and a slip of $3.33 \%$. With $\sigma=3 \mathrm{MS} / \mathrm{m}$ and permeabilities: a) $\mu=500$, b) $\mu=1000$ and c) $\mu=6000$.

The magnetic field of the rotor is tangential to the sheet thus creating a North Pole and a South Pole where the current changes sign. The interaction of both magnetic fields at torque and sliding level, assuming the direction of currents shown in the figure 8 , causes magnetic dipoles that distort the magnetic field created in the stator. By modeling vectorialy the field lines, a reduction of the total magnetic field in the superior peripheral zone of the sheets is noticed due to the opposition between the rotor and the stator fields, whereas in deeper sheet zones both fields add their contributions.

This distortion of the total magnetic field can be seen in the following figure 9 given for various values of the rotor sheets relative permeability. The magnetic field lines reach greater depth in motors with solid rotors than in those with sheet, diminishing its net torque. As well as this, the angular deviation that the net field undergoes, diminishes as conductivity increases. This effect is more significant in the sheet motor that in the solid motor.

\section{PARASITIC CURRENTS}

Using simulation and a normal section test, it is possible to know the induction in a rotor (figures 10 and 11).

With this distribution, the e.m.f. results [10]:

$$
E=-\frac{\partial \phi}{\partial t}=-\frac{\partial B}{\partial t} S=-S \cdot B \cdot w_{S} \cdot \cos w_{S} t
$$

Where $S$ is the magnetic circuit area, a constant in this case. 


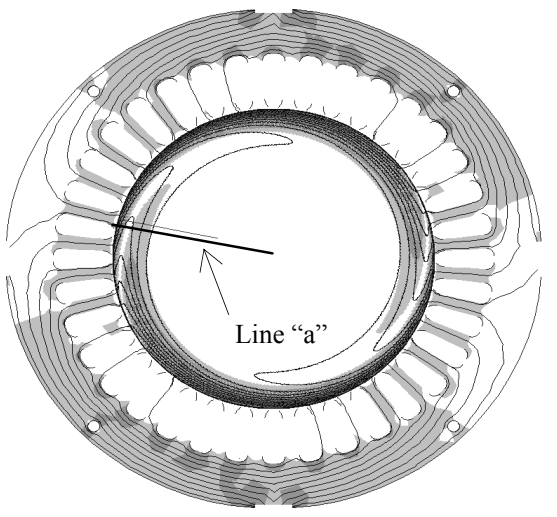

Fig. 10. Magnetic simulation with FEMM. Line "a" represents the section of simulation of the fig 11 .

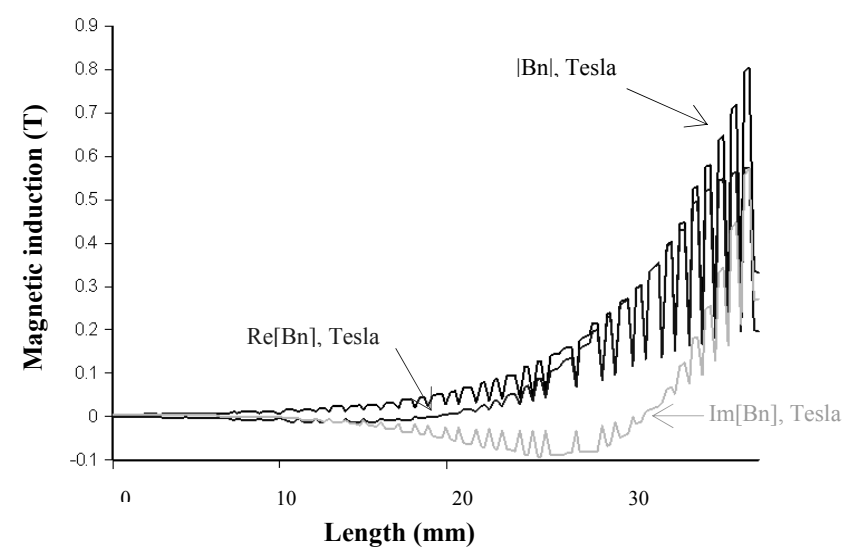

Fig. 11. Magnetic induction. Sheet rotor at $3000 \mathrm{rpm}, \sigma=3 \mathrm{MS} / \mathrm{m}$, $\mu=4000 \mathrm{H} / \mathrm{m}$, and $\mathrm{f}=3.33 \mathrm{~Hz}$.

The current induced by this EMF in sheets can be calculated using the respective electric circuits, remembering that current flows inside the sheets. The EMF distribution is shown in figure 12.

This distribution is owing to the EMF in the upper area of the sheets inducing a higher current in this section (see figure 13). The maximum current can be calculated ( $r$ is the height of the sheets from the rotor axis center):

$$
\begin{gathered}
\left|\bar{E}_{1}\right|=\int_{R_{\text {axis }}}^{h} \frac{k}{(A-r)} d r=k \cdot \ln \frac{A-R_{\text {axis }}}{A-h} \\
\left|\bar{E}_{2}\right|=\int_{h}^{R_{\text {stator }}} \frac{k}{(A-r)} d r=k \cdot \ln \frac{A-h}{A-R_{\text {stator }}} \\
R_{\text {sheet }}=\left(R_{1}+R_{2}\right)=\rho_{\text {sheet }} \frac{L_{\text {rotor }}}{e_{\text {sheet }}}\left(\frac{\left(R_{\text {stator }}-s\right)}{h \cdot\left(R_{\text {stator }}-h-s\right)}\right) \\
\left(E_{1}-E_{2}\right)=I\left(R_{1}+R_{2}\right)=k \cdot \ln \left[\frac{(A-h)^{2}}{\left(A-R_{\text {axis }}\right) \cdot\left(A-R_{\text {stator }}\right)}\right]
\end{gathered}
$$

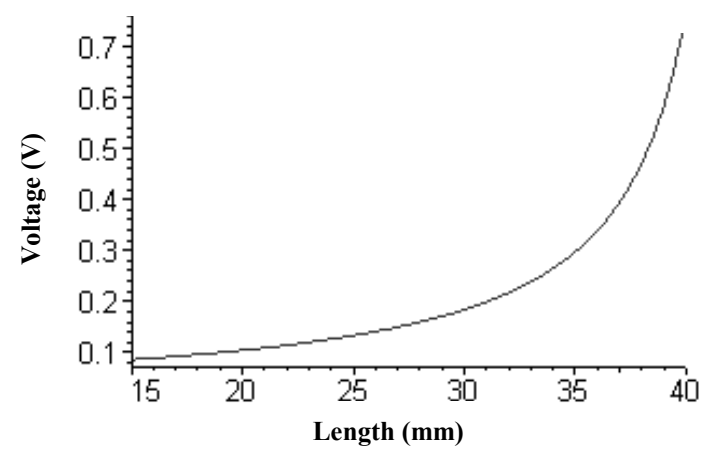

Fig. 12. EMF distribution (distance from stator axis).

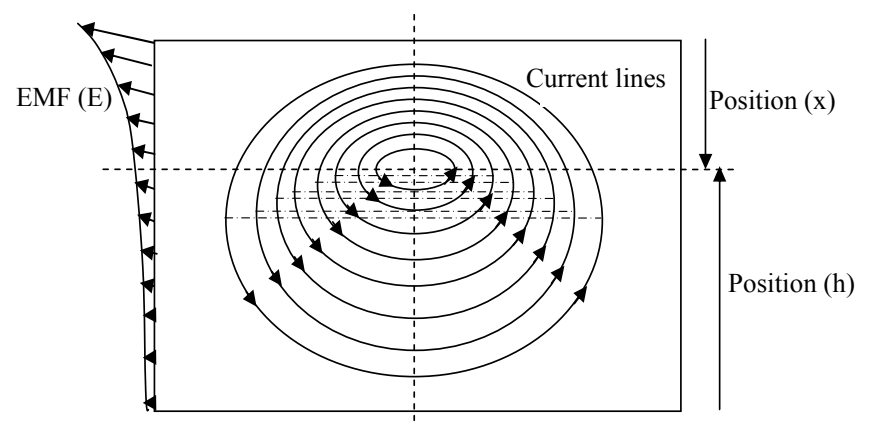

Fig. 13. Vertical coordinate defining the current sense change.

$$
I=\frac{k \cdot \ln \left[\frac{(A-h)^{2}}{\left(A-R_{\text {axis }}\right) \cdot\left(A-R_{\text {stator }}\right)}\right]}{\frac{\rho_{\text {sheet }} \cdot L_{\text {rotor }}}{\rho_{\text {sheet }}}\left(\frac{\left(R_{\text {stator }}-s\right)}{\left(h \cdot\left(R_{\text {stator }}-h-s\right)\right)}\right)}
$$

Where the constants $A, K, \mathrm{y} k$, are values that adjust the electromagnetic field equation; $s$ is a parameter that depends upon the current circulating through the upper sheet area. Also, $h$ is the sheet radius; $\mathrm{e}_{a x i s}$ the sheet thickness (mm); $\sigma$ is the sheet conductivity $\left(\mathrm{S} \cdot \mathrm{m} / \mathrm{mm}^{2}\right)$ and $L_{\text {rotor }}$ is the rotor length.

As the induction is a function of the radial position of the considered section, which is known; it is possible to calculate the constants $A$ and $K$ :

$$
\begin{gathered}
B_{\max }=\frac{K}{\left(A-R_{\text {stator }}\right)} ; A=\frac{B_{\min } \cdot R_{\text {rotor }}-R_{\text {stator }} \cdot B_{\max }}{B_{\min }-B_{\max }} \\
B_{\min }=\frac{K}{\left(A-R_{\text {rotor }}\right)} ; K=B_{\min } \cdot\left(A-R_{\text {rotor }}\right)
\end{gathered}
$$

And $k$ is a constant function of maximum emf:

$$
\begin{gathered}
E=\frac{k}{(A-r)} ; \quad k=E_{\max -2}\left(A-R_{\text {stator }}\right) \\
E_{\max -2}=E_{\max -1} \cdot\left(\frac{m_{1}}{m_{2}}\right) \cdot\left(\frac{Z_{2} \cdot \xi_{2}}{Z_{1} \cdot \xi_{1}}\right)
\end{gathered}
$$




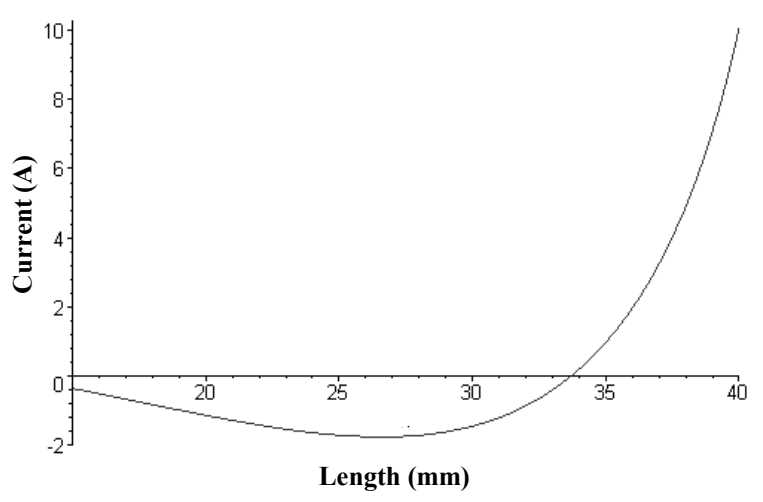

Fig. 14. Distribution of the active current along the radial sheet of the rotor.

\section{Where:}

$-m_{1}$ and $m_{2}=$ number of phases of stator and rotor.

$-Z_{1}$ and $Z_{2}=$ number of turns and sheets of stator and rotor. - $\xi_{1}$ and $\xi_{2}=$ distribution factors for stator and rotor.

All the terms are known except the radial coordinate $h$ which corresponds to a change of sense in current along the shape profile.

With the coordinate $h$ known, it is possible to calculate the total sheet current, by integration of the current equation between the upper a lower limits of the sheet (the distribution of the active current along the radial sheet is shown in figure 14):

$$
\begin{aligned}
& I_{\text {upper }} \\
& \int_{h}^{R_{\text {stator }}}\left[\ln \left[\frac{k \cdot e_{\text {sheet }}}{\rho_{\text {sheet }} \cdot L_{\text {rotor }}}\right) \cdot\left(\frac{(A-h)^{2}}{\left(A-R_{\text {axis }}\right) \cdot\left(A-R_{\text {stator }}\right)}\right] \cdot\left[\frac{h\left(R_{\text {stator }}-h-s\right)}{\left(R_{\text {stator }}-s\right)}\right] \cdot\right] \cdot d h \\
& I_{\text {lower }}=
\end{aligned}
$$

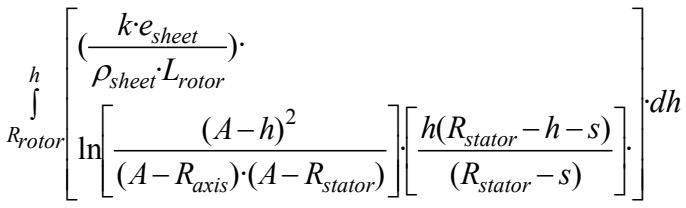

The ring per-sheet current and the total currents are:

$$
\begin{aligned}
& I_{\text {ring-per-sheet }}=I_{\text {upper }}-I_{\text {lower }} \\
& I_{\text {total-ring }}=\frac{I_{\text {ring-per-sheet }}}{2 p} \frac{n_{\text {rotor-sheets }}}{\pi}
\end{aligned}
$$

The torque is related to this total current:

$$
\begin{aligned}
\tau= & \int_{R_{\text {rotor }}}^{R_{\text {stator }}} L_{\text {rotor }} \cdot B(r) \cdot I(r) \cdot d h= \\
= & L_{\text {rotor }} \cdot \int_{R_{\text {rotor }}}^{R_{\text {stator }}}\left[\left(\frac{K}{(A-h)}\right) \cdot\left(\frac{k \cdot e_{\text {sheet }}}{\rho_{\text {sheet }} \cdot L_{\text {rotor }}}\right)\right. \\
& \cdot \ln \left(\frac{(A-h)^{2}}{\left(A-R_{\text {axis }}\right) \cdot\left(A-R_{\text {stator }}\right)}\right) . \\
& \left.\cdot\left(\frac{h \cdot\left(R_{\text {stator }}-h-s\right)}{\left(R_{\text {stator }}-s\right)}\right)\right] \cdot d h
\end{aligned}
$$

\section{ELECTROMAGNETIC ANALYSIS OF SPIRAL SHEET ROTOR TYPE A, AT 3000 RPM}

The expressions in this section allow for the observation of magnetic induction, current density and voltage induced in the sheet motor at any point $P$ of the air gap, rotor or stator. All the mathematic development of the following expressions can be consulted in Mujal et al. [22].

\section{A) Electromagnetic field created by the slots in the stator} $\left(\boldsymbol{\beta}_{\mathrm{s}}\right)$ :

Taking in account that the currents will affect each slot of the stator in a different way, and each one will create magnetic fields in concordance, we have for the component in $x$, and in $y$, of the magnetic field:

$$
\begin{aligned}
\left|\bar{B}_{x-\text { total }}\right|= & {\left[\begin{array}{l}
\sum_{i=1}^{i=6}\left|\bar{B}_{i}\right| \cos \gamma_{i}+\left(\frac{1}{2}\right) \sum_{i=7}^{i=12}\left|\bar{B}_{i}\right| \cos \gamma_{i}-\left(\frac{1}{2}\right) \sum_{i=13}^{i=18}\left|\bar{B}_{i}\right| \cos \gamma_{i} \\
-\sum_{i=19}^{i=24}\left|\bar{B}_{i}\right| \cos \gamma_{i}-\left(\frac{1}{2}\right) \sum_{i=25}^{i=30}\left|\bar{B}_{i}\right| \cdot \cos \gamma_{i}+\left(\frac{1}{2}\right) \sum_{i=31}^{i=36}\left|\bar{B}_{i}\right| \cdot \cos \gamma_{i}
\end{array}\right]+} \\
+ & {\left[\begin{array}{l}
\left(\frac{\sqrt{3}}{2}\right) \sum_{i=7}^{i=12}\left|\bar{B}_{i}\right| \cos \gamma_{i}+\left(\frac{\sqrt{3}}{2}\right) \sum_{i=13}^{i=18}\left|\bar{B}_{i}\right| \cos \gamma_{i} \\
\left.-\left(\frac{\sqrt{3}}{2}\right) \sum_{i=25}^{i=30}\left|\bar{B}_{i}\right| \cos \gamma_{i}-\left(\frac{\sqrt{3}}{2}\right) \sum_{i=31}^{i=36}\left|\bar{B}_{i}\right| \cos \gamma_{i}\right]
\end{array}\right.} \\
\left|\bar{B}_{y-\text { total }}\right|= & {\left[\begin{array}{l}
\sum_{i=1}^{i=6}\left|\bar{B}_{i}\right| \operatorname{sen} \gamma_{i}+\left(\frac{1}{2}\right) \sum_{i=7}^{i=12}\left|\bar{B}_{i}\right| \operatorname{sen} \gamma_{i}-\left(\frac{1}{2}\right) \sum_{i=13}^{i=18}\left|\bar{B}_{i}\right| \operatorname{sen} \gamma_{i} \\
-\sum_{i=19}^{i=24}\left|\bar{B}_{i}\right| \operatorname{sen} \gamma_{i}-\left(\frac{1}{2}\right)_{i=25}^{i=30}\left|\sum_{i}\right| \cdot \operatorname{sen} \gamma_{i}+\left(\frac{1}{2}\right) \sum_{i=31}^{i=36}\left|\bar{B}_{i}\right| \cdot \operatorname{sen} \gamma_{i}
\end{array}\right]+} \\
+ & {\left[\begin{array}{l}
\left(\frac{\sqrt{3}}{2}\right) \sum_{i=7}^{i=12}\left|\bar{B}_{i}\right| \operatorname{sen} \gamma_{i}+\left(\frac{\sqrt{3}}{2}\right) \sum_{i=13}^{i=18}\left|\bar{B}_{i}\right| \operatorname{sen} \gamma_{i} \\
\left.-\left(\frac{\sqrt{3}}{2}\right)_{i=25}^{i=30}\left|\bar{B}_{i}\right| \operatorname{sen} \gamma_{i}-\left(\frac{\sqrt{3}}{2}\right) \sum_{i=31}^{i=36}\left|\bar{B}_{i}\right| \operatorname{sen} \gamma_{i}\right]
\end{array}\right.}
\end{aligned}
$$

Where $B_{i}$ are the magnetic induction values for each slot of the stator, and $\operatorname{sen} \gamma_{i}, \cos \gamma_{i}$ depend on geometric parameters (see Mujal et al [22]). Thus the expression of the total magnetic field created by the stator at a point $P$ is:

$$
B_{\text {total }}(t)=\sqrt{B_{x-\text { total }}^{2}+B_{y \text {-total }}^{2}} ; \quad \alpha_{B_{\text {Total }}}(t)=\operatorname{arctg} \frac{B_{y \text {-total }}}{B_{x-\text { total }}}
$$



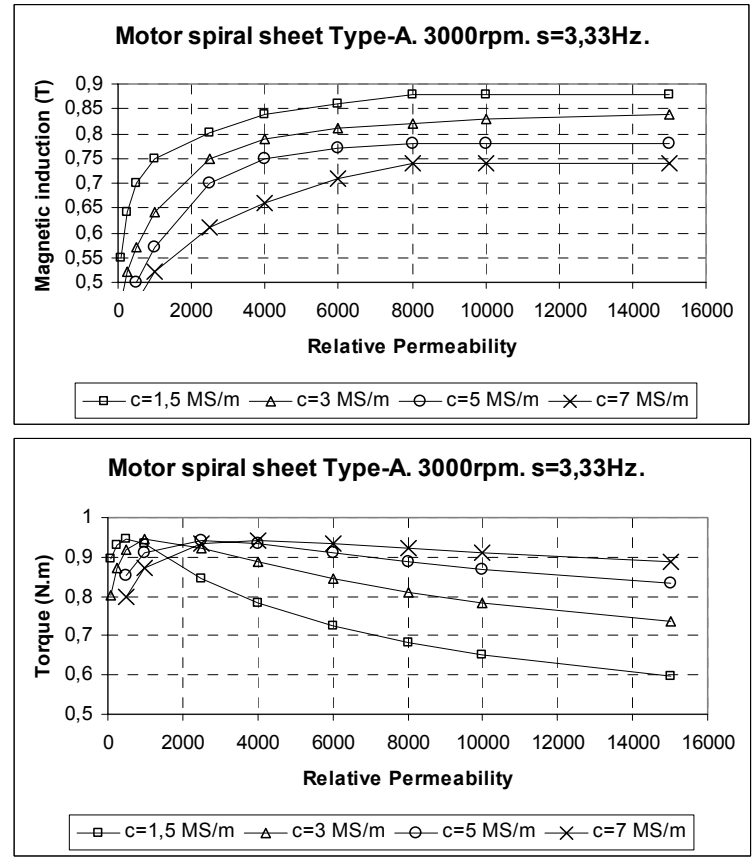

Fig. 15. Variation magnetic induction and torque in the air gap in relation to conductivity.

\section{B) Electromotive force created by the magnetic field originated in the stator $(V)$}

The magnetic field of the stator creates a sinusoidal magnetic flux, which induces an electromotive force at each point of the motor and sheets of the rotor (see Mujal et al [22]). This emf $\mathrm{V}$, will be determined for the current of the slot, i, by:

$$
\begin{aligned}
\vec{V} & =\int \frac{\partial}{\partial t}\left|\bar{B}_{\text {Total }}\right| \cdot d S_{\text {flux }}+\int\left(\vec{v}_{\text {rotor }} \times \bar{B}_{\text {total }}\right) d L_{\text {rotor }}= \\
& =\int \frac{\partial}{\partial t}\left|\bar{B}_{\text {total }(x, y)}\right| \frac{L_{\text {rotor }}}{2 \cdot \sqrt{\left(R_{R E}^{2}-x^{2}\right)}}(-2 \cdot x) \cdot d x+ \\
& +\left[s \cdot w \cdot y \cdot\left|\bar{B}_{y-\text { total }}\right|-s \cdot w \cdot x \cdot\left|\bar{B}_{x-\text { total }}\right|\right]
\end{aligned}
$$

Knowing emf $V$ (in $\mathrm{V}$ ) and the conductivity of the sheets $\sigma$ (in $\mathrm{S} / \mathrm{m}$ ), it is possible to calculate the current density and the current which will pass through each sheet:

$$
\begin{gathered}
\bar{J}_{\text {sheet }}=\sigma_{\text {sheet }}(-\nabla \bar{V})=-\sigma_{\text {sheet }}\left(\frac{\partial V}{\partial x}, \frac{\partial V}{\partial y}\right) \\
\left|\bar{I}_{\text {sheet }}\right|=\int\left|\bar{J}_{\text {sheet }}\right| \cdot d S_{\text {sheet }}
\end{gathered}
$$

Finally, as the electrical resistance $R_{\text {elec }}(\Omega)$ is known, it is also possible to determine the rest of the sheet's electrical parameters (impedance $Z_{\text {elec }}(\Omega)$; inductive reactance $X_{\text {elec }}(\Omega)$ )

$$
\begin{gathered}
\left|\bar{Z}_{\text {elec-sheet }}\right|=\frac{\left|V_{\text {sheet }}\right|}{\left|\bar{I}_{\text {sheet }}\right|} \\
R_{\text {elec-sheet }}=\rho_{\text {sheet }} \cdot \frac{L_{\text {eng-sheet }}}{S_{\text {sheet }}} \mathfrak{I}_{\text {elec-sheet }}=\frac{X_{\text {elec-sheet }}}{2 \cdot \pi \cdot f}
\end{gathered}
$$
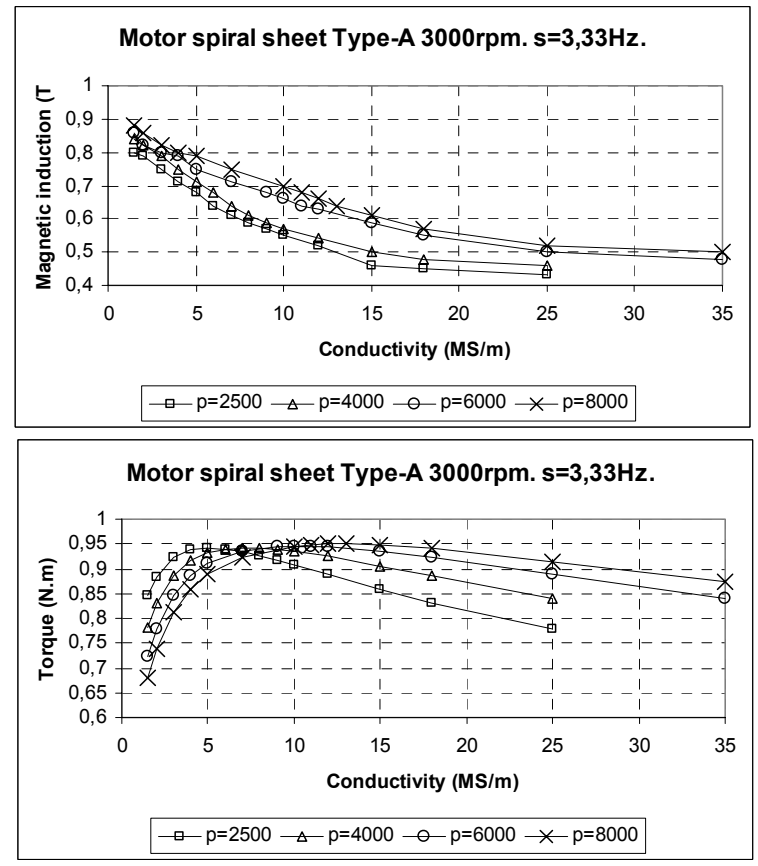

Fig. 16. Variation magnetic induction and torque in the air gap in relation to permeability.

\section{C) Electromagnetic field created by the rotor $\left(\beta_{r}\right)$}

The process undertaken to determine the magnetic field created by the currents of the stator in the point $P$ of the rotor, should be repeated again for another point $Q$ of the rotor, in order to obtain the emf between this two points (see Mujal et al [22]). By this way, it is possible to calculate the magnetic field that this emf generates in the rotor. In order to do so, the curvature of the sheets to straight segments $L i$ that pass through their centre is assimilated. As the spiral sheet rotor type $A$ contains 270 sheets, there is a turn of $1.4^{\circ}$ for each sheet, which is the contribution of current $k_{i}$, which each segment will give based on the $(r, t)$ :

$\bar{H}_{T}=\sum \bar{H}_{i}=\sum_{i=1}^{i=150}\left[\begin{array}{l}\frac{K_{1} \cdot L_{1}}{2 \cdot\left|\bar{x}_{1}\right|} \cdot\left(-\cos \alpha_{1}, \operatorname{sen} \alpha_{1}\right)+ \\ \frac{K_{2} \cdot L_{2}}{2 \cdot\left|\bar{x}_{2}\right|} \cdot\left(-\cos \alpha_{2}, \operatorname{sen} \alpha_{2}\right)\end{array}\right]=\frac{\bar{B}_{T}}{\mu_{o} \cdot \mu_{\text {sheets }}}$

Where:

$$
x_{1}=\frac{\left(R_{\text {Shaft }}-L_{2} \cdot \cos \alpha_{2}\right)-x}{\cos \alpha_{1}} \quad x_{2}=\frac{\left(R_{\text {Shaft }}-x\right)}{\cos \alpha_{2}}
$$

\section{MAGNETIC RELUCTANCE OF THE ROTOR SHEETS}

The relative permeability of the rotor sheets is an influence at several electrical magnitudes. Thus, if the sheets have high permeability, the reluctance of the magnetic circuit will be low, and the magnetic flow will be more superficial [11] [23].

As well as that part, as shown in figure 15 , with low values of permeability the value of torque and magnetic induction increase suddenly, while with high values of permeability the magnetic induction becomes stabilized and the torque drops smoothly. Although normal values of sheets permeability do not exceed $8000 \mathrm{H} \cdot \mathrm{m}^{-1}$, the simulation has been carried out for values up to $15000 \mathrm{H} \cdot \mathrm{m}^{-1}$ in order to better visualize the evolution of such magnitude. 


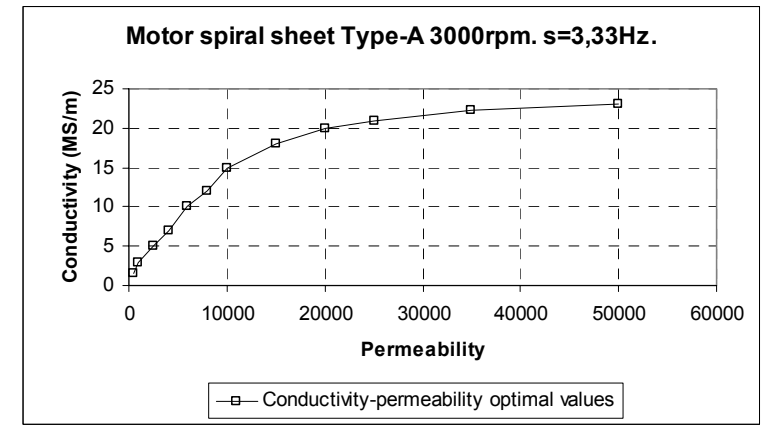

Fig. 17. Optimum values of conductivity-permeability of the sheets, in order to obtain the maximum values of torque and efficiency.

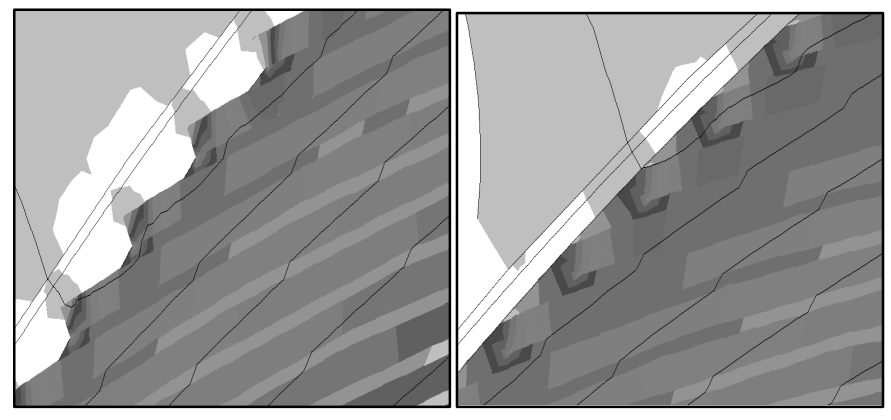

Fig. 18. Geometric shape of the rotor magnetic field in a sheet before and after mechanized.

\section{ANALYSIS OF CONDUCTIVITY}

Figure 16 shows the simulations that have been obtained with FEMM program, using the same 3000 rpm motor, working at a frequency of $5 \mathrm{~Hz}$. Modeling for different conductivity and permeability values of the rotor sheets (p) and a slip value of $3.33 \%$ is obtained the torque and induction.

From these graphs and with different conductivities and relative permeability of the sheets it is possible to obtain a representation with the optimum values of conductivitypermeability, which lets us to obtain the highest values of torque and performance (see fig. 17) [24] [25].

\section{SHEET MOTOR BEHAVIOR}

All the analyses have been carried out for the $3000 \mathrm{rpm}$ motor with a slip of $3.33 \mathrm{~Hz}$ at full load.

\section{A) Effect of the rotor mechanization (edge effect)}

Two identical rotors have been built to study this effect. The type $A$ rotor have the sheet edges mechanized whereas in the rotor type $B$ the edges are unmechanized (see fig. 18). In principle, sheet edges cause a variable air gap, introducing modifications in the magnetic field and weakening its total value, which has repercussions in the rest of the electromagnetic values [18] [22] [24].

As it can be seen in figure 19, this effect depends on the conductivity in such a way that up to a conductivity of $3 \mathrm{MS} / \mathrm{m}$ (sheets standard value) the torque in the air gap increases, resulting in values of 0.94 and 0.84 N.m for the $A$ and $B$ rotors, respectively. Over this conductivity value the torque decreases for all the rotors.
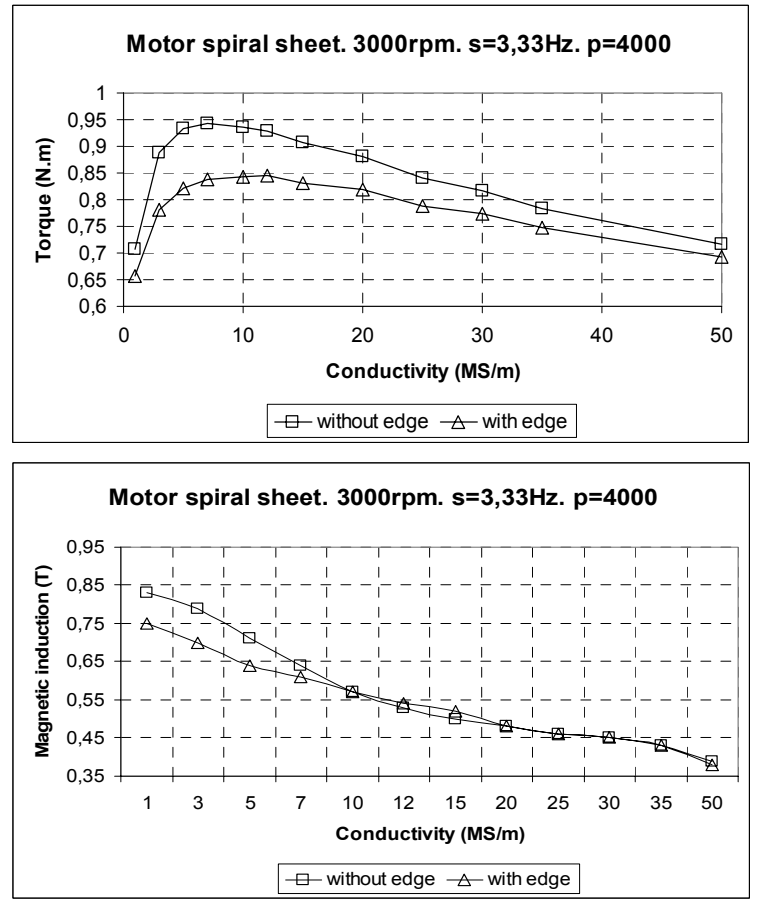

Fig. 19. Torque and magnetic induction in the gap vs. conductivity and mechanizing of the rotor. Rotors Type $A$, and $B$. ( $\mathrm{s}=\mathrm{slip}, \mathrm{p}=$ relative permeablity).

On the other hand, the magnetic induction (Fig. 19) in the air gap decreases from the beginning with values of 0.81 and $0.70 \mathrm{~T}$ for the motors $A$ and $B$ at a conductivity of $3 \mathrm{MS} / \mathrm{m}$. Finally, for high sheet conductivity values, differences in torque and induction in relation to rotor mechanization type are minimal.

\section{B) Rings effect on the sheet rotors}

To analyze this effect, three identical rotors have been built. Type $A$ rotor has side rings, type $C$ motor does not have such rings whereas type $D$ rotor also has a central ring [10] [11] [19].

Besides its mechanical properties which increase the rigidity of the rotor structure, the side rings constitute a way back for the external currents that generate torque. This avoids these currents to close in the inner half of the sheets, which implies not generating opposite torques. For this reason the final net motor torque is greater in motors with side rings rotor.

If comparing the two first rotors (types $A$ and $C$ ), it can be seen that torque, intensity, absorbed power and efficiency maximum values are greater for the type $A$ rotor $(5.75 \mathrm{~N} \cdot \mathrm{m}$, $3.15 \mathrm{~A}, 1790 \mathrm{~W}$ and $20.2 \%)$ than for the type $C(4.5 \mathrm{~N} \cdot \mathrm{m}, 2.6 \mathrm{~A}$, $1610 \mathrm{~W}$ and $17.1 \%)$. Such torque increase $(21 \%)$ is consistent with that of the sheets effective length when rings are incorporated, and that is of $20 \%$ when calculating by the following expressions:

$$
\frac{\tau_{\text {without-rings }}}{\tau_{\text {with-rings }}}=\Delta L \% \quad \Delta L \%=\left(1-\frac{L_{\text {rotor }}}{L_{\text {rotor }}+\Delta L_{\text {rotor }}}\right) \cdot 100
$$



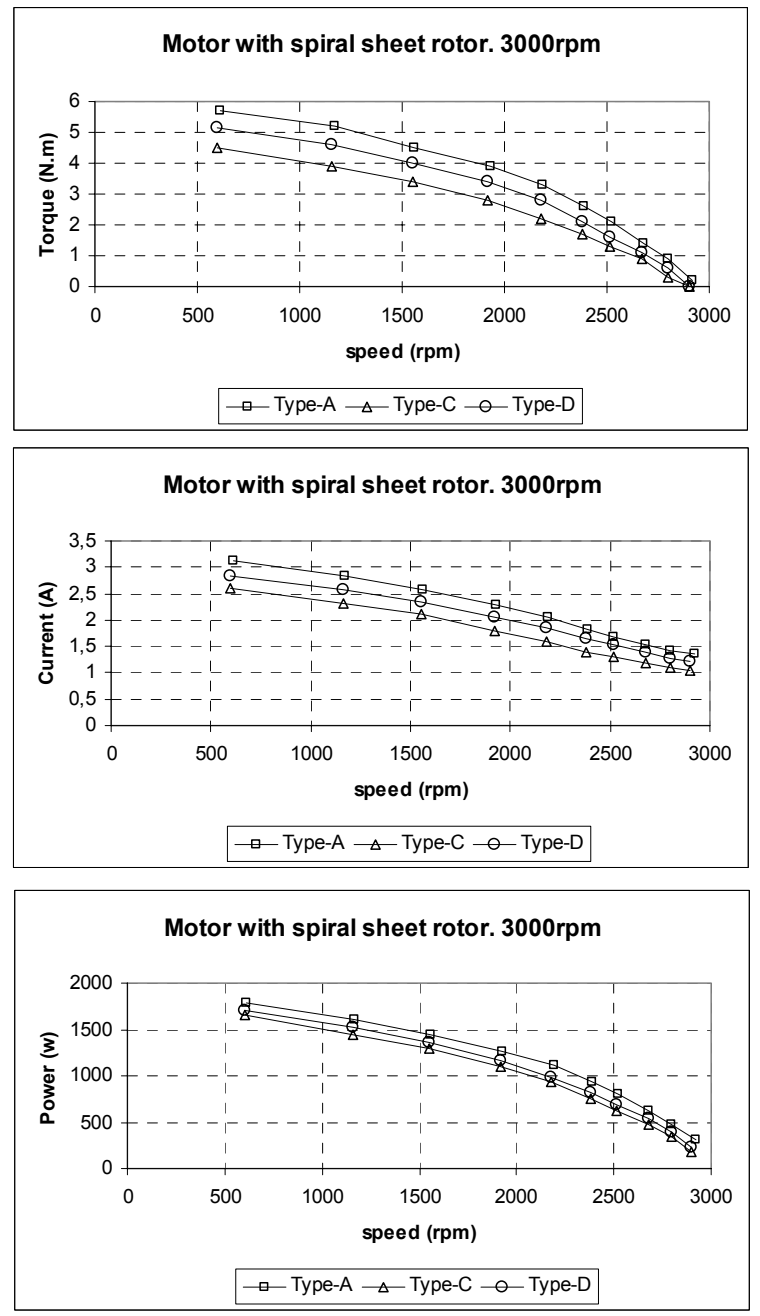

Fig. 20. Evolution of different electrical magnitudes in the spiral sheet motor, type $A$ and $F$.

$$
\begin{gathered}
\Delta L_{\text {sheets-rotor }}=\left[\frac{D_{\text {rotor }}}{2 \cdot p^{2}} \cdot \frac{S_{\text {effective-sheets }}}{S_{\text {rings }}} \cdot \frac{n^{\mathbf{o}}{ }_{\text {sheets-rotor }}}{\pi} \cdot \frac{\rho_{\text {rings }}}{\rho_{\text {sheets }}}\right] \\
S_{\text {effective-sheet }}=e_{\text {sheet }} \cdot L_{\text {effective }} \quad\left[L_{\text {effective }}\right]=\left[\frac{\rho^{2}}{2 \cdot R}\right]_{R}^{R E} \\
R=R_{\text {stator }}-h_{\text {ring }}
\end{gathered}
$$

Where:

$P=$ pairs of poles.

$D_{\text {rotor }}=$ rotor diameter $(\mathrm{mm})$

$S_{\text {effective-sheet }}=$ effective surface of the sheet $\left(\mathrm{mm}^{2}\right)$.

$S_{\text {ring }}=$ surface of the rotor ring $\left(\mathrm{mm}^{2}\right)$.

$\rho_{\text {ring } ;} \rho_{\text {sheet }}=$ ring and sheet material resistivity $\left(\Omega \cdot \mathrm{mm}^{2} / \mathrm{m}\right)$.

However, as it can be seen in fig. 20, incorporating a central ring ( $A$ and $D$ rotors) causes a decrease of the maximum obtained values. The new values for the torque, intensity, absorbed power and efficiency are $5.10 \mathrm{~N} \cdot \mathrm{m}, 2.85 \mathrm{~A}, 1715$ and $18.8 \%$, respectively. This results in a $11 \%$ decrease of the
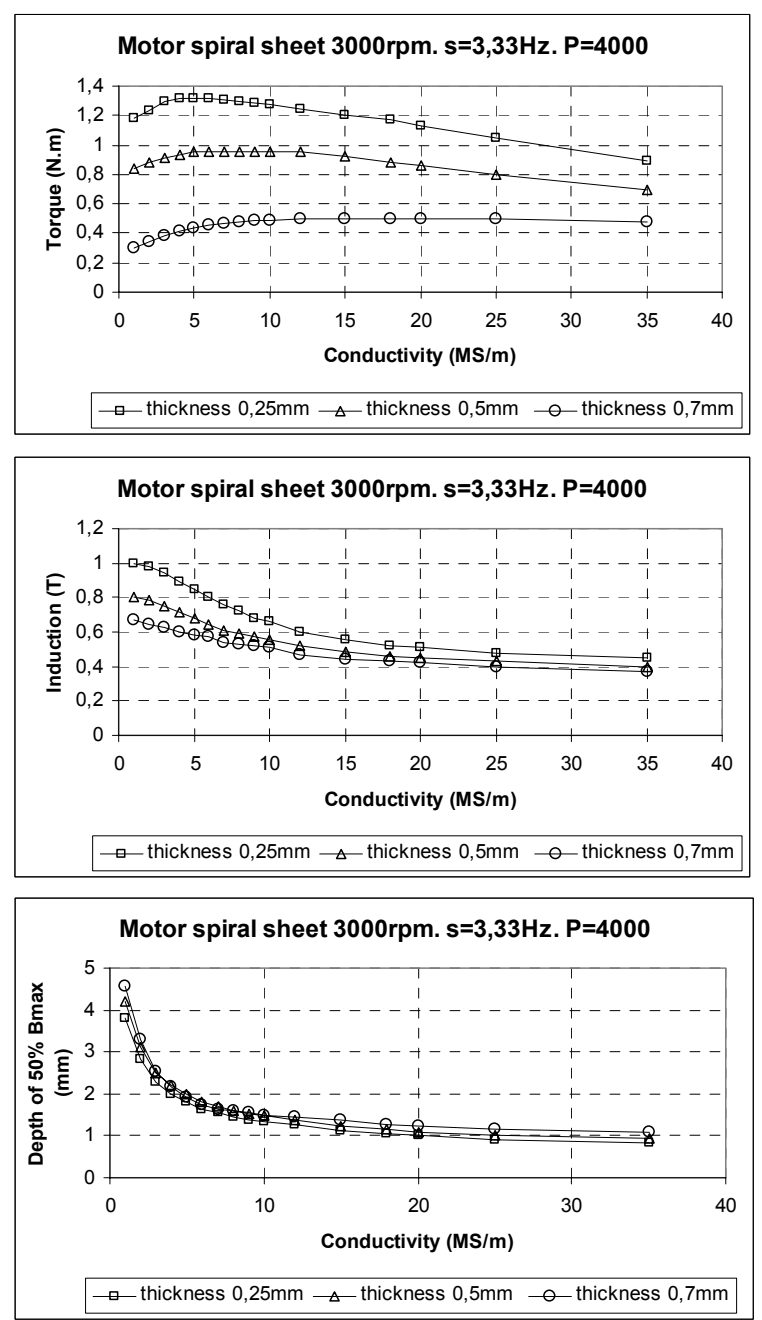

Fig. 21. Evolution of electrical magnitudes vs conductivities for various sheets thickness ( $\mathrm{s}=\mathrm{slip}, \mathrm{p}=$ relative permeablity).

torque, and in a $10 \%$ sheet effective length decrease if applying the former expressions. This suggests that a linear dependency between the sheets effective length and the obtained values of the net torque exists.

\section{C) Effect of the sheets number on the sheet rotor}

Three identical rotors with different number of sheets have been constructed to study this effect: rotor type $A$, with 270 sheets and $0.25 \mathrm{~mm}$ thick; $E$ rotor with 160 sheets and $0.5 \mathrm{~mm}$ thick; and $F$ rotor with 118 sheets and $0.7 \mathrm{~mm}$ thick [9] [19] [22].

When sheets thickness is increased sheets compaction becomes more difficult and therefore the air gap between them also increases. Such air gaps between sheets hinder the magnetic flux, increasing the rotor reluctance and deepening the torque generating currents (this depth is radially measured from the air gap to the rotor axis). For this reason the resulting torque and the induction in the motor air gap decrease. On the other hand, if the sheets conductivity and permeability increase, the effect of the differences on the sheet thickness 

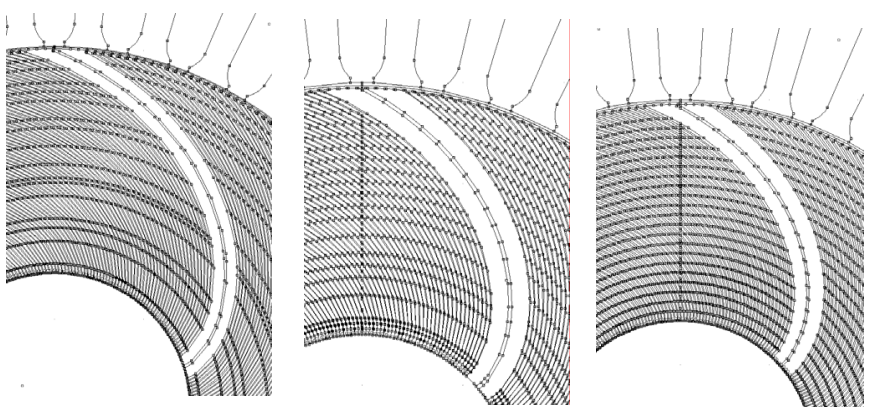

Fig. 22. Different curvatures of the sheets a) curve 1, b) curve 2, c) curve 3 .

becomes less important due to the fact that the reluctance drops and the magnetic flux increases consequently. This implies the flux lines remaining closer to the surface and magnifying the field created by the rotor, which results in a weaker net magnetic field. Such phenomenon is only possible if a large phase shift between the field created by the stator and the field created by the sheet rotor exists. This phase shift originates a change in the reluctance and reactance values of the rotor. In this way a higher conductivity implies a more inductive charge, which creates more power reactive. The optimization in the selection of the materials goes through evaluate the product of the primary intensity and the power factor of the motor, being this parameter extremely important as it is applicable to all motor components, which allows optimizing the materials.

By supposing little variations in rotor reactance, as it occurs when slip frequency has a low value, the phase variation between rotor intensity and electromotive force is estimated by means of the next equation:

$$
|I| \propto \frac{1}{X_{\text {rotor }}}-\frac{1}{2 \cdot X_{\text {rotor }}^{3}} \cdot R_{\text {rotor }}^{2}
$$

As it can be appreciated in fig. 21, taking the reference conductivity of $3 \mathrm{MS} / \mathrm{m}$ as the standard value of the sheets, the torque values in the air gap are $1.3,0.9$, and $0.4 \mathrm{~N} \cdot \mathrm{m}$ for thickness values of $0.25,0.5,0.7 \mathrm{~mm}$, respectively. On the other hand, the optimum conductivity from which torque decreases is not the same for all the sheet thickness values, being of 4,8 and $12 \mathrm{MS} / \mathrm{m}$ for the aforementioned cases. The magnetic induction and the torque generating currents depth decrease with increasing thickness. But whereas there are important differences in the magnetic induction values depending on the sheet thickness $(0.95,0.75$ and $0.62 \mathrm{~T}$ for thickness of $0.25,0.5$ and $0.7 \mathrm{~mm}$ at $3 \mathrm{Ms} / \mathrm{m}$ ), such differences are negligible when analyzing the torque generating currents depth at $50 \%$ of the maximum induction, being $2 \mathrm{~mm}$ for all the thickness values.

\section{D) Effect of the sheet curvature on the sheet rotor}

Three identical rotors have been simulated and tested to study this effect (types $A, G$, and $H$ ) (see fig. 22). The $A$ rotor has the curvature of an enveloping circle (perfectly piled sheets). The $H$ rotor has a very open curvature (with a greater separation in the outer side of the sheets). Finally, the $G$ rotor has an intermediate curvature [10] [19] [24].
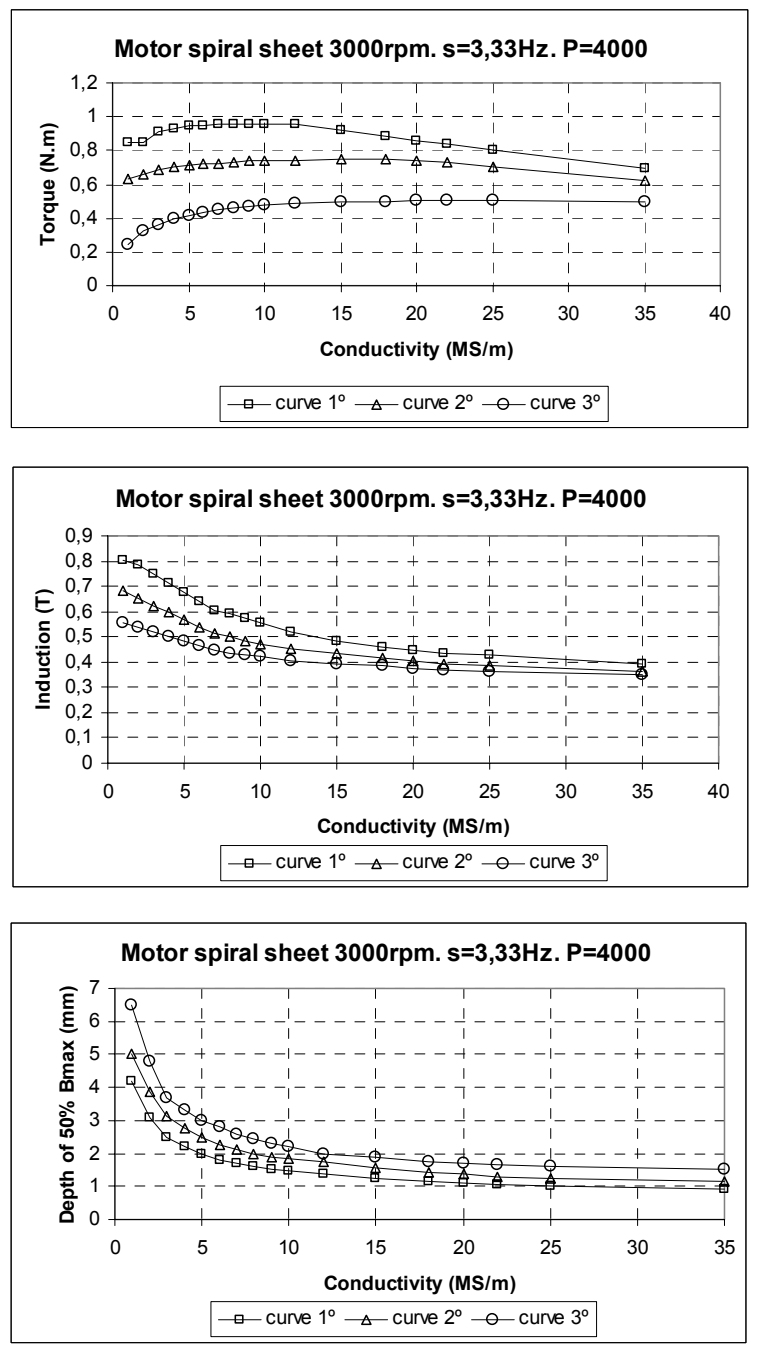

Fig. 23. Evolution of electrical magnitudes vs conductivities for several sheets curvatures. ( $\mathrm{s}=\mathrm{slip}, \mathrm{p}=$ permeablity relative).

The containing air sections between rotor sheets are decisive in the creation of the motor characteristic reluctance. If happening at small scale ( $A$ rotor), this phenomenon is positive since it facilitates a quick response in the transients, which is highly interesting. However, if such high reluctance is accompanied by low inertia, it results in low electrical and mechanical constants.

But with larger spaces between sheets ( $G$ and $H$ rotors), as it happened with the effect of sheet thickness, the magnetic flux path is hindered. This increases the rotor reluctance and the torque generating currents depth so the resulting torque and the induction in the air gap decrease. Also in this occasion, if sheet conductivity or permeability are increased, the effect of the sheet curvature becomes less relevant due to the fact that the reluctance is lower and consequently the magnetic flux is greater, remaining the flux lines close to the surface and increasing the field created by the rotor, which results in a weaker net magnetic field.

As it can be seen in fig. 23, by taking the reference conductivity of $3 \mathrm{MS} / \mathrm{m}$ as the standard value of the sheets, the torque values in the air gap are $0.93,0.68$, and $0.35 \mathrm{~N} \cdot \mathrm{m}$ for the $A, G$ and $H$ rotors, respectively. 
However, the optimum conductivity from which torque decreases is not the same for all the sheet curvatures, being of 5, 10 and $14 \mathrm{MS} / \mathrm{m}$ for the $A, G$ and $H$ rotors. For low conductivities the magnetic induction decreases with increasing sheet curvature. And for a conductivity of $3 \mathrm{MS} / \mathrm{m}$, its values for the rotors $A, G$ and $H$ are $0.75,0.63$ y $0.52 \mathrm{~T}$, respectively. Finally, the torque generating currents depth at $50 \%$ of the maximum induction increases from the beginning, being $2.5,3.2$ and $3.7 \mathrm{~mm}$ for the aforementioned rotors.

\section{EXPERIMENTAL VALUES}

\section{A) Electrical values:}

The graphs in fig. 24 compare the evolution of several electrical magnitudes for the motor with sheet rotor type A, in three speed regimes. What can be inferred from the analysis is that efficiency increases considerably when the speed regime increases, but this variation is more considerable beyond 1000 $\mathrm{rpm}$ and up to $1500 \mathrm{rpm}$. Also, for the $3000 \mathrm{rpm}$ regime there is a better torque curve since, despite displaying lower absolute values, it has a reduced slope and therefore a larger interval of speeds with optimal torque values. The intensity curve is favorable to the $3000 \mathrm{rpm}$ regime since, although it displays an initial peak, its values quickly decrease, showing lower levels in a great interval of speeds. From the analysis of the remaining magnitudes represented, the motor's best performance is confirmed at high speed regimes.

It could be considered, with reference to the graphs, that these motors show good performance, but this occurs with elevated slip values, when compared with the squirrel cage motor. Nevertheless this is not a problem since these motors can work perfectly with these slip values as proven by the mechanical and thermal analysis [10] [11] [24].

\section{B) Motors comparison:}

Table II shows the characteristic values for the sheet motor type $A$ in comparison with other conventional motors, that have been compared in previously published papers [10] [11] and [26] by the same authors. The values are given for the 3000 rpm motor, and two operation regimens: rated, and maximum

\section{C) Mechanical inertias and losses:}

Studies have been undertaken of mechanical losses due to bearings, fan and air friction and the results are completely acceptable and compatible with those obtained for other classic motors such as the cage motor or solid rotor (see Table III) [24] [26].

Figure 25 shows the results for the test to determine the current and torque versus speed in a stop-start cycle, for the squirrel cage motor, the winding motor and the type A sheet motor. From this comparison it can be seen that torque values are $6.50 \mathrm{~N} \cdot \mathrm{m}, 4.35 \mathrm{~N} \cdot \mathrm{m}$, and $5.75 \mathrm{~N} \cdot \mathrm{m}$ for the squirrel cage, solid rotor and sheet-A motors, respectively, and 9.68A, $4.46 \mathrm{~A}$ and $3.16 \mathrm{~A}$ in the case of intensity. This confirms that sheet motors are specially indicated to stop-start cycles, almost matching the cage motor torque values but with intensities 2.5 times lower. In comparison to the winding motor, the intensity results are similar but the torque is significantly greater in sheet motors, proving its better behavior for this regimes.

Acceleration tests have been undertaken in a vacuum, no important deviations with respect to the cage motors can be perceived, although in a worst case scenario, a slight increase was observed in the sheet motors when the foils were not superficially mechanized on the outside of the rotor.

Finally, there are no mechanical resistance problems or prolonged operational deformations for the sheet motors, and although these motors have not been designed for such prolonged usage but rather for frequent stop-start regimes, they have perfectly surpassed the tests carried out running continuously for more than 4 hours.

\section{D) Thermal values:}

Thermal experiments demonstrate that the motors present different characteristics with respect to conventional squirrel cage motor, since the current, that is the main cause of the increase of the temperature in the stator winds, practically does not change when changing the load, as shown in figure 26. This makes these motors able to work in regimes with high slip without changing their thermal conditions. This fact is almost impossible in squirrel cage motors [24] [27] [28] and [29] [30].

Also it can be seen that the slip does not influence the temperature when the motor works at low speed regimes (1000 and $1500 \mathrm{rpm})$, whereas differences exist at high regimes $(3000 \mathrm{rpm})$ although without being considered important. 

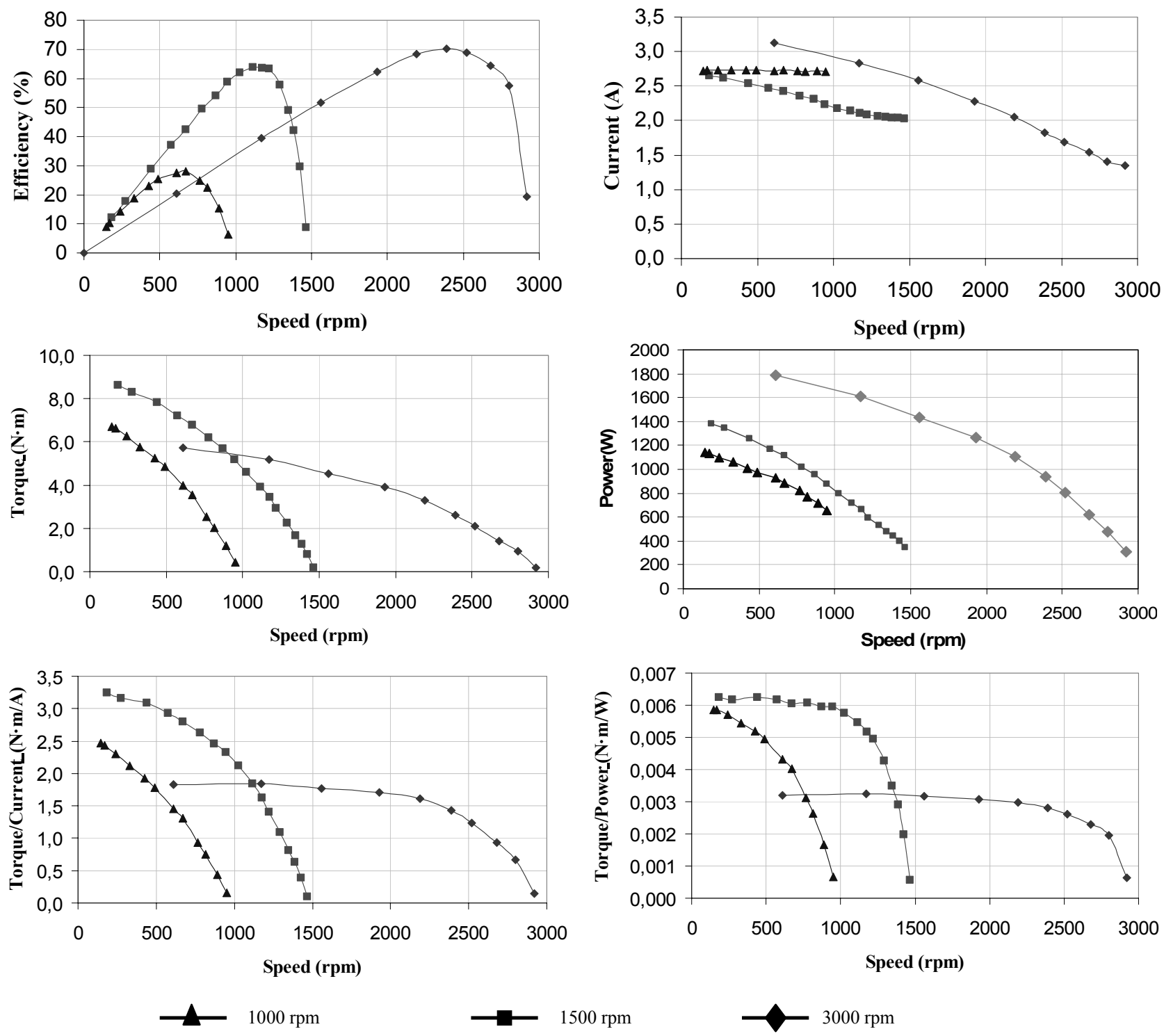

Fig. 24. Experimental results using motor with spiral sheet rotor type $A$ at different speeds.

TABLE II

MAIN ELECTRICAL CHARACTERISTICS OF MOTORS AT 3000RPM

\begin{tabular}{|c|c|c|c|c|c|}
\hline Electrical parameters & $\begin{array}{l}\text { Squirrel cage } \\
\text { rotor }\end{array}$ & $\begin{array}{l}\text { Solid rotor } \\
\text { with rings }\end{array}$ & $\begin{array}{l}\text { Winding } \\
\text { rotor }\end{array}$ & $\begin{array}{l}\text { Diamagnetic } \\
\text { hollow rotor }\end{array}$ & $\begin{array}{c}\text { Rotor with spiral } \\
\text { sheets type } A\end{array}$ \\
\hline Maximum torque $(\mathrm{N} \cdot \mathrm{m})$ & 7.59 & 4.68 & 6.42 & 2.66 & 5.72 \\
\hline Maximum power (W) & 5051 & 2826 & 4230 & 1403 & 1790 \\
\hline Maximum current (A) & 9.64 & 4.87 & 7.63 & 5.30 & 3.13 \\
\hline Maximum efficiency $(\%)$ & 77.8 & 47.40 & 73.6 & 50.0 & 70.1 \\
\hline Maximum useful power (W) & 1766 & 615 & 1365 & 303 & 788 \\
\hline Torque/Current $(\mathrm{N} \cdot \mathrm{m} / \mathrm{A})$ & 1.55 & 0.97 & 1.68 & 0.50 & 1.84 \\
\hline Torque/Power $(\mathrm{N} \cdot \mathrm{m} / \mathrm{W})$ & 0.00264 & 0.0018 & 0.00276 & 0.0019 & 0.0032 \\
\hline Power Factor & 0.91 & 0.93 & 0.92 & 0.90 & 0.92 \\
\hline Vacuum current (A) & 0.728 & 1.023 & 1.168 & 0,565 & 1.346 \\
\hline Short-circuit current (A) & 9.803 & 5.260 & 8.060 & 5.845 & 3.630 \\
\hline Rated current (A) & 2.510 & 1.480 & 2.25 & 1.620 & 1.410 \\
\hline Rated torque (N.m) & 3.84 & 0.97 & 2.76 & 0.44 & 0.94 \\
\hline Rated Power (W) & 1492 & 627 & 1180 & 267 & 480 \\
\hline Rated efficiency (\%) & 75.2 & 45.4 & 68.6 & 48.4 & 57.5 \\
\hline
\end{tabular}


TABLE III

VALUES OF MECHANICAL LOSSES OF THE ROTORS TESTED

\begin{tabular}{cccc}
\hline \hline Rotor Type & $\begin{array}{c}\text { Losses }(\mathbf{W}) \\
\text { at 1000 } \mathbf{~ p m}\end{array}$ & $\begin{array}{c}\text { Losses (W) } \\
\text { at 1500 rpm }\end{array}$ & $\begin{array}{c}\text { Losses }(\mathbf{W}) \\
\text { at 3000 rpm }\end{array}$ \\
\hline Squirrel cage & 10 & 15 & 32 \\
Solid rotor & 15 & 32 & 60 \\
Winding rotor & 23 & 48 & 96 \\
Hollow rotor & 45 & 102 & 136 \\
Spiral sheets A & 18 & 38 & 72 \\
\hline \hline
\end{tabular}
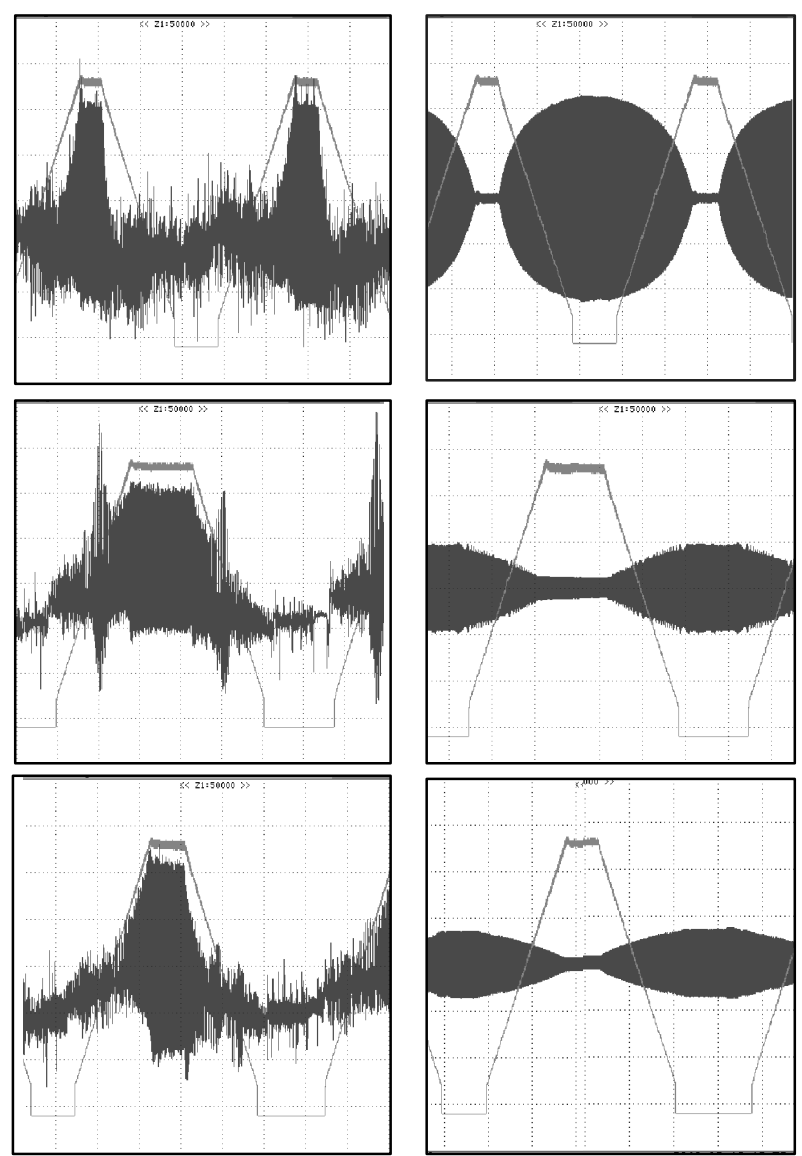

Fig. 25. Torque-current vs speed in a stop-start cycle: a) Squirrel cage rotor, b) Solid rotor with rings, c) Spiral sheet rotor type $A$

Range: Torque: $1.45 \mathrm{~N} \cdot \mathrm{m} /$ div, Current: $6.15 \mathrm{~A} / \mathrm{div}$

\section{CONCLUSIONS}

Motors with spiral sheet rotors, display a high starting torque in relation to the short circuit current, and are also able to work in a wide slip range without thermal or mechanical problems. This presumably makes them suitable for actions requiring a high number of stop-starts, as well as very variable regimes. Presently there are innumerable operations with these characteristics, among which we can highlight small spinning motors in textile industries, the operations involved in domestic electrical appliances, machines tools, etc. therefore representing a wide market range.
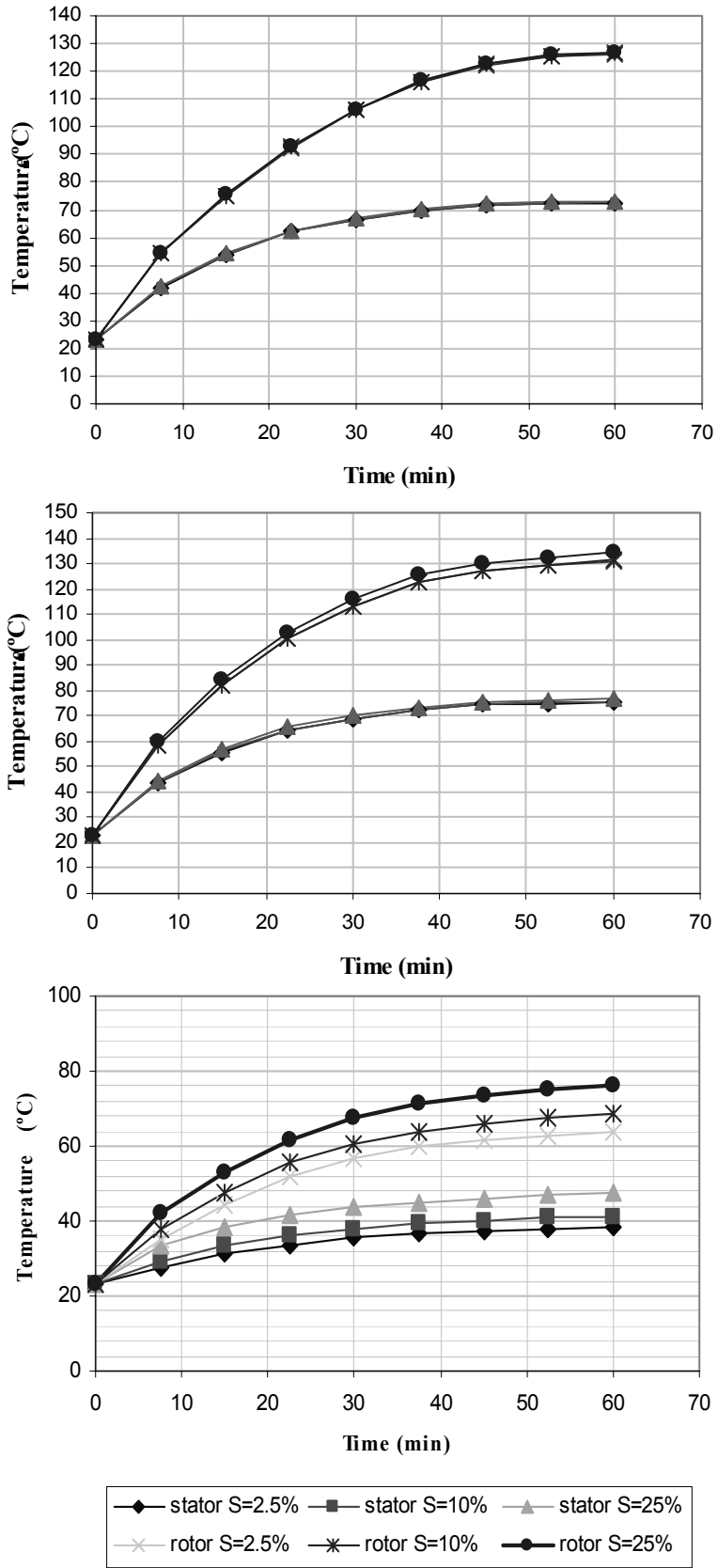

Fig. 26. Thermal test of motor with spiral sheet rotor type $A$ at 1000, 1500 and $3000 \mathrm{rpm}$ : evolution of rotor-stator temperature.

Also, it has been shown that these motors work better at high speeds and reduced sizes (textile spinning motors) while their main drawback is the high cost of machine tooling required to create the rotor sheets, thus requiring mass production techniques.

\section{ACKNOWLEDGMENT}

The authors would like to acknowledge the economic support received from the "Ministerio de Ciencia y Tecnología de España" for supporting this work under the DPI 200403180 Research Project. 


\section{REFERENCES}

[1] J.F. Lindsay and T.H. Barton, "Parameter Identification for Squirrel Cage Induction Machines," IEEE Transactions on Power Apparatus and Systems, vol. 92, no. 1, pp. 1287-1291, January 1996.

[2] Xiaoping Tu, L.-A. Dessaint, R. Champagne, K. Al-Haddad, "Transien Modeling of Squirrel-Cage Induction Machine Considering Air-Gap Flux Saturation Harmonics," IEEE Trans. on Industrial Electronics, vol. 55, no. 7, pp. 2798-2809, July 2008.

[3] M.E. Zaim, "Non-linear models for the design of solid rotor induction machines," IEEE Transactions on Magnetics, vol. 35, no. 3, pp. 13101313, May 1999.

[4] M.Z. Wellingtong, "Experimental investigation of an induction motor for high speed solid rotor and composites," IEEE Transactions on Electrical Machines, vol. 32, pp. 204-215, no. 6, July 2000

[5] D. Gonen, "Analysis of a 2-Phase Drag-Cup Induction machine," IEEE Transactions On Power Apparatus And Systems, vol. 85, no. 1, pp. 7176, January 1966.

[6] M. Apstein, L.M Blum, "Low-Inertia Induction Motors," Transactions of the American Institute of Electrical Engineers, vol. 76, no. 3, pp. 253-257, April 1957.

[7] M.R. Krishnamurthy, V. Veluchamy, "Polyphase Induction Machine with Hollow Ferromagnetic Rotor," IEEE Transactions on Power Apparatus and Systems, vol. 91, no. 4, pp. 1686-1691, July 1972.

[8] A.M. Oliveira, P. Kuo-Peng, N. Sadowski, F. Runcos, R. Carlson, P. Dular, "Finite-element analysis of a double-winding induction motor with a special rotor bars topology," IEEE Transactions on Magnetics, vol. 40, no. 2-2, pp. 770-773, March 2004.

[9] R.M Rosas, O.B. Aragones, X.C. Fajula, A.R Blanco, "Behavior of the Three-Phase Induction Motor With Spiral Sheet Rotor," IEEE Transactions Energy Conversion, vol. 24, no. 1, pp. 68 - 76, March 2009.

[10] R.M. Rosas, O.B. Aragones, X.C. Fajula, "Induction motor with spiral sheet rotor," IEEE International Symposium Industrial Electronics, pp. $529-537$, July 2009

[11] R. Mujal Rosas, O. Boix Aragones, G. Marin, "Three-phase induction motor with spiral sheet rotor," IEEE International Symposium Industrial Electronics, pp. 455 - 460, June 2008.

[12] E. Levi, "Multiphase Electric Machines for Variable-Speed Applications," IEEE Trans. on Industrial Electro. vol. 55, no. 5, pp. 1893-1909, May-08.

[13] D. Platt, "Reluctance motor with strong rotor anisotropy," Industry Applications Society, vol. 1, no. 1, pp. 224-229, October 1990.

[14] J.W. Lee, H.S. Kim, B.I. Kwon, B.T. Kim, "New rotor shape design for minimum torque ripple of SRM using FEM," IEEE Transactions on Magnetics, vol. 40, no. 2-2, pp. 754-757, March 2004.

[15] Y. Komatsu, Y. Kawabata, M. Kobayashi, T. Kawabata, E.C. Ejiogu, "New induction machine rotor constants," Industrial Electronics ISIE'96, vol. 2, no. 1, pp. 900-904, June 1996.

[16] M.P. Krefta, O. Wasynezuk, "A Finite Element based State Model of Solid Rotor Synchronous Machines," IEEE Transactions on Energy Conversion, vol. EC-2, no. 1, pp. 21-30, March 1987.

[17 ] M. Sarma, "Current-density distribution in solid rotor induction motor," IEEE Transactions on Magnetics, vol. 15, no. 6, pp. 1473-1475, Nov 1979.

[18] R. Mujal, "Electromagnetic analysis of the induction motor with spiral sheet rotor," European Conference on Power Electronics and Applications 2005, September 2005.

[19] R. Mujal, O. Boix, "Improvement of three phase induction motor with spiral sheet rotor," IEEE International Symposium on Industrial Electronics, pp. 1107-1112, June 2007.

[20] R. Dutta, M.F. Rahman, "Design and Analysis of on induction machine with Very Wide Constant Power Operation Range," IEEE Industrial Electronics IECON'06, vol. 2, no. 1, pp. 1375-1380, November 2006.
[21] Etien, E. Chaigne, C. Bensiali, N., "On the Stability of Full Adaptive Observer for Induction Motor in Regenerating Mode," IEEE Trans. on Industrial Electronics, vol. 57, no. 5, pp. 1599 - 1608, May 2010

[22] R. Mujal, O. Boix, P.J. Gamez, R. Castilla, J. Lloveras, "Experimental Analysis of the Three-Phase Induction Motor with Spiral Sheet Rotor," Journal Electrical Engineering, no. 9, pp. 251-261, December 2009.

[23] A. Das, K. Sivakumar, R. Ramchand, C. Patel, K. Gopakumar, "A Pulsewidth Modulated Control of Induction Motor Drive Using Multilevel 12-Sided Polygonal Voltage Space Vect," IEEE Trans. on Industrial Electronics, vol. 56, no. 7, pp. 2441-2449, July 2009.

[24] R. Mujal-Rosas, H. Navarrete, O. Boix-Aragones, X. Colom, "Electromagnetic analysis of the induction motor with spiral sheet rotor," European Conference on Power Electronics and Applications 2007, pp. 1-10, September 2007.

[25] S. Bolognani, L. Peretti, M. Zigliotto, "Design and Implementation of Model Predictive Control for Electrical Motor Drives," IEEE Trans. on Industrial Electronics, vol. 56, no. 6, pp. 1925-1936, June 2009.

[26] R. Mujal-Rosas, O.B. Aragones, "Electromagnetic analysis of the induction motor with spiral sheet rotor," European Conference on Power Electronics and Applications 2005, pp. 10-20, September 2005.

[27] B. Cranganu-Cretu, A. Kertesz, J. Smajic, "Coupled ElectromagneticThermal Effects of Stray Flux: Software Solution for Industrial Applicati," IEEE Trans. on Industrial Electronics, vol. 57, no. 1, pp. 1421, Jan 2010

[28] K. Hafiz, G. Nanda, N. C. Kar, "Performance Analysis of Aluminumand Copper-Rotor Induction Generators Considering Skin and Thermal Effe," IEEE Trans. on Industrial Electronics, vol. 57, no. 1, pp. 181192, Jan 2010.

[29] R. Wrobel, N. McNeill, P. H. Mellor, "Performance Analysis and Thermal Modeling of a High-Energy-Density Prebiased Induc," IEEE Trans. on Industrial Electronics, vol. 57, no. 1, pp. 201-208, Jan 2010.

[30] A. Boglietti, A. Cavagnino, D. Staton, M. Shanel, M. Mueller, C. Mejuto, "Evolution and Modern Approaches for Thermal Analysis of Electrical Machines," IEEE Trans. on Industrial Electronics, vol. 56, no. 3, pp. 871-882, March 2009

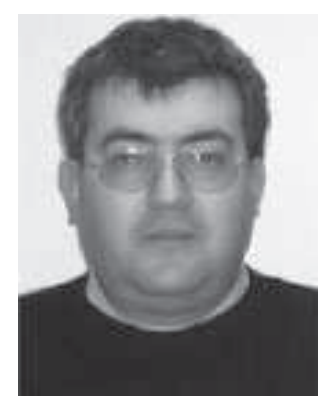

Ramon Mujal-Rosas received the B.S. degree in Electrical Engineering and the Ph.D. degree in Electrical Engineering from the Technical University of Catalonia, Terrassa, Spain, in 1993 and 2004, respectively.

$\mathrm{He}$ is a currently a Professor in the Department of Electrical Engineering, Technical University of Catalonia. He is the author of some books about electrical subjects, and is engaged in the areas of renewable energies and especially wind power and electrical machines.

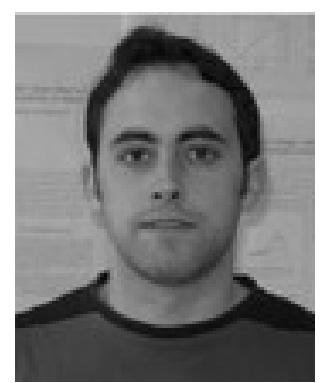

Jordi Orrit-Prat received the degree in physics from the University of Barcelona in 2003. Then he started to work with the ETSEIAT at the Technical University of Catalonia, (UPC) in Terrassa, Spain. Currently he is assistant professor at that university.

$\mathrm{He}$ is also member of the Laboratory of Physics of Dielectric Materials, (DILAB) and has focused his research on the electrical properties of insulating materials. $\mathrm{He}$ is carrying out his $\mathrm{PhD}$ research in conduction mechanisms of XLPE insulated power cables. 